\title{
Regulation of mains voltage and reactive power with the help of a synchronous compensator by two-axis excitation
}

\author{
Nurali Pirmatov ${ }^{1}$, Allabergen Bekishev ${ }^{1 *}$, Safar Shernazarov ${ }^{1}$, Najmiddin Kurbanov $^{2}$, \\ Usmon Norkulov ${ }^{3}$ \\ ${ }^{1}$ Tashkent State Technical University named after Islam Karimov, Tashkent, Uzbekistan \\ ${ }^{2}$ Karshi State Engineering and Economic Institute, Karshi, Uzbekistan \\ ${ }^{3}$ Tashkent Chemical-Technological Institute, Tashkent, Uzbekistan
}

\begin{abstract}
The article describes the design of a synchronous compensator with biaxial excitation and its automatic excitation control system. In addition, the issues of ensuring the required voltage level at fixed points using synchronous compensators with biaxial excitation were considered. In addition, the U-shaped characteristic of a synchronous generator with biaxial excitation was obtained.
\end{abstract}

\section{Introduction}

A synchronous compensator (SC) is a synchronous motor that operates in idle mode, i.e., no load on the shaft. The active power consumed by it (if we neglect the no-load losses) $\mathrm{P}_{\mathrm{sc}} \sim 0$, and the $\mathrm{SC}$ is loaded only with the reactive current. Compared to a conventional synchronous motor, SK is manufactured with a lightweight shaft; they have smaller dimensions and weight.

At present, the synchronous compensator of longitudinal and transverse excitation (type KSP-320-2) is one of the controlled sources of reactive power, which are manufactured based on a hydrogen-water-cooled turbogenerator TGV-300M. These compensators, possessing high technical and economic indicators, are primarily intended for use in high and extra-high voltage networks to ensure the required voltage levels at specified points of the network (nodes of their connection), reduce electrical energy losses in power transmission lines, increase conductivity and stability. [1-4].

\section{Methods}

The reactive power produced by a synchronous compensator can be found using the following formula:

$$
Q_{s c}=\sqrt{3} \cdot I_{s c}=U_{l} \frac{U_{l}-E_{q}}{X_{d}}
$$

\footnotetext{
*Corresponding author: allabergen1386@umail.uz
} 
where $\mathrm{X}_{\mathrm{d}}$ is the reactance of the synchronous compensator along the $\mathrm{d}$ axis; $\mathrm{U}_{\mathrm{L}}$ is mains voltage;

The value and sign of the reactive power of the SC depend on the ratio between the electromotive force $(E M F) E_{q}$ and $U_{L}$ - the voltage at the point of the network where the $S C$ is connected. $\mathrm{E}_{\mathrm{q}}$ is determined by the value of the excitation current, and an increase in the excitation current corresponds to an increase in $\mathrm{E}_{\mathrm{q}}$. If $\mathrm{E}_{\mathrm{q}}=\mathrm{U}_{\mathrm{L}}$, the reactive power of the $\mathrm{SC}$ $\mathrm{Q}_{\mathrm{sc}}=0$. With an increase in the excitation current (overexcitation) $\mathrm{E}_{\mathrm{q}}>\mathrm{U}_{\mathrm{L}}$ and the $\mathrm{SC}$ generates reactive power into the network, and the current generated by the $\mathrm{SC}, \mathrm{I}_{\mathrm{sc}}$, is ahead of the $\mathrm{U}_{\mathrm{sc}}$ voltage by $90^{\circ}$. An under-excitation mode can be obtained by reducing the excitation current, then $\mathrm{E}_{\mathrm{q}}<\mathrm{U}_{\mathrm{L}}$ and Isc lags behind by $90^{\circ}$ from voltage $\mathrm{U}_{\mathrm{sc}}$. In this mode, the $\mathrm{SC}$ consumes reactive power, receiving it from the network. The rated power of the synchronous compensator $\mathrm{Q}_{\text {sc.nom }}$ is indicated for the overexcitation mode. According to the design features associated with the heating conditions of the windings, in the underexcitation mode, $\mathrm{Q}_{\mathrm{sc}}=0.5 \mathrm{Q}_{\text {sc.nom }}$.

\section{Results and Discussion}

In figure 1 shows the U-shaped characteristic obtained as a result of the experiment of a synchronous compensator with a power of $12 \mathrm{~kW}$, a voltage of $220 \mathrm{~V}$, and a rotational speed of $1500 \mathrm{rpm}$.

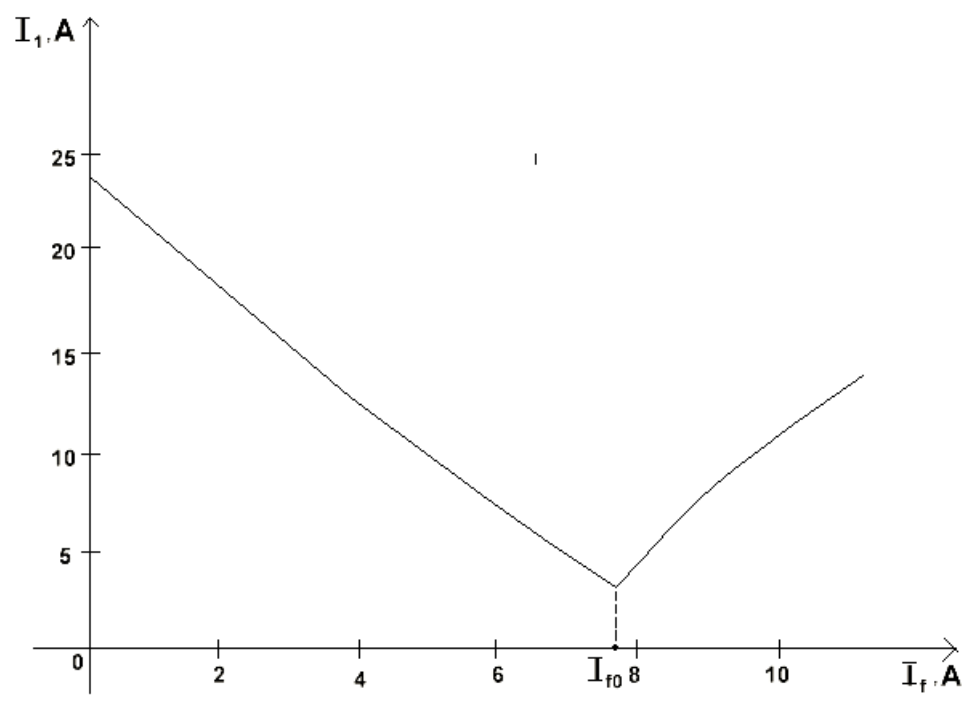

Fig-1. U-shaped characteristic of a synchronous compensator with biaxial excitation with a power of $12 \mathrm{~kW}$, a voltage of $220 \mathrm{~V}$, a rotation speed of $1500 \mathrm{rpm}$.

Figure 1 shows the excitation current in the range from 0 to $\mathrm{I}_{\mathrm{f} 0}$; the synchronous compensator operates in the under-excitation mode, with values exceeding $\mathrm{I}_{\mathrm{f} 0}$, it operates in the overexcitation mode. In the under-excitation mode, the EMF of the synchronous compensator with biaxial excitation is less than the mains voltage, that is, $\mathrm{E}_{\mathrm{q}}<\mathrm{U}_{\mathrm{L}}$, in the overexcitation mode of the synchronous compensator, the EMF exceeds the mains voltage $\mathrm{U}_{\mathrm{L}}$, that is, $\mathrm{E}_{\mathrm{q}}>\mathrm{U}_{\mathrm{L}}$. This means that in synchronous compensators with biaxial excitations, it will be possible to smoothly and automatically adjust reactive power in a wide range $\pm \mathrm{Q}_{\mathrm{sc}}$ to increase and decrease the voltage compared with conventional synchronous compensators [8]. 
When choosing the power of the SC, it is found for the overexcitation mode, based on the desired voltage $\mathrm{U}_{2 \text { des }}$ :

$$
Q_{s c}=\frac{U_{2 d e s}-U_{2 n b}}{\mathrm{X}} \cdot U_{2 \mathrm{des}}
$$

where: $\mathrm{X}$ is the resistance of the network to which the SC is connected.

The positive properties of SC as sources of reactive power are:

- the possibility of increasing the generated power if the voltage in the network decreases;

- the possibility of smooth and automatic regulation of reactive power, both in the direction of increasing and decreasing the voltage.

Disadvantages of SK:

- the presence of rotating parts requires the presence of service personnel;

- $\quad$ the cost of $1 \mathrm{kVar}$ of power generated by the SC is often higher than $1 \mathrm{kVar}$ generated by the static capacitor banks SCB.

The use of synchronous compensators as a compensating device is illustrated in Figure2. The voltage at the end of the line before installing the compensator is determined by the expression:

$$
\Delta U=U_{1}-\frac{P_{N} \cdot \mathrm{R}+Q_{N} \cdot \mathrm{X}}{U_{2}}
$$

Let $\mathrm{U}_{2}$ be lower than desired. When the $\mathrm{SC}$ operates in the overexcitation mode, $\mathrm{Q}_{\mathrm{sc}}$ is issued to the network, the reactive power flow decreases, the voltage loss decreases, and $\mathrm{U}_{2}$ increases, determined by the following expression:

$$
U_{2}=U_{1}-\frac{P_{N} \cdot \mathrm{R}+\left(Q_{N}-Q_{s c}\right) \cdot \mathrm{X}}{U_{2}}
$$

If $\mathrm{U}_{2}$ is higher than the desired one, the $\mathrm{SC}$ is switched to under-excitation mode. Then $\mathrm{Q}_{\mathrm{sc}}$ is consumed from the network, the flow through the reactive power network increases, the voltage loss increases, and $\mathrm{U}_{2}$ decreases, determined by the following expression:

$$
U_{2}=U_{1}-\frac{P_{N} \cdot \mathrm{R}+\left(Q_{N}+Q_{s c}\right) \cdot \mathrm{X}}{\mathrm{U} 2}
$$

When overexcited, the SC generates reactive power:

$$
Q_{\text {sc.over }}=Q_{\text {sc.nom }}
$$

With under-excitation, the SC consumes reactive power:

$$
Q_{\text {sc.un-ex }}=0.5 \cdot Q_{\text {sc.nom }}
$$

This leads to an increase in voltage losses in the network and a decrease in voltage at consumers. Under-excitation of synchronous compensators can be used when it is necessary to reduce the voltage, for example, in the mode of the lowest loads.

A synchronous compensator (SC) is a traditional reactive power generator used in modern power systems and controlled consumers. 
The generation (output) or consumption mode is determined by the excitation of the SC. Following its U-shaped characteristic (Fig. 1) at nominal excitation ( $\mathrm{I}_{\text {ex.nom}}$ ), the synchronous compensator delivers reactive power:

$$
Q_{\text {sc.nom }}=\frac{\mathrm{U}_{\mathrm{In}}\left(\mathrm{E}_{\mathrm{q} . \mathrm{nom}}-\mathrm{U}_{\mathrm{w}}\right)}{\mathrm{x}_{\mathrm{d}}}
$$

and in the absence of excitation $(1 \mathrm{EX}=0)$ - consumes reactive power:

$$
\left|-Q_{\text {sc.nom }}\right|=\frac{\mathrm{U}_{I n}^{2}}{\mathrm{x}_{\mathrm{d}}} \approx 0,5 \cdot Q_{\text {sc.nom }}
$$

The largest possible load of the SC with the consumed reactive power is achieved either at the boundary negative excitation current $-\mathrm{I}_{\text {ex.bor. }}$ or in the absence of excitation (IEX $=0$ ) and the internal angle of the compensator $\delta=\pi / 2$, i.e., when the rotor is located along the transverse axis.

Where in

$$
\left|-Q_{\text {sc.bor }}\right|=\frac{\mathrm{U}_{I n}^{2}}{\mathrm{x}_{\mathrm{q}}} \approx 0,75 \cdot Q_{\text {sc.nom }}
$$

The boundary mode of consumption of reactive power is determined by the condition of the stability of the SC operation - maintaining synchronism. Synchronizing torque is created by synchronous electromagnetic $\mathrm{Mc}$ and reactive (due to salient polarity) $\mathrm{Mr}$ moments.

With negative excitation, the highest consumed reactive power $\mathrm{Q}_{\text {s.bor }}$ is theoretically achieved in the boundary mode at $\delta=0$. In practice, due to the presence of active power losses (for ventilation, friction), the power $\mathrm{Q}_{\text {sc.bor }}$ is achieved at an angle $\delta "=\pi / 10$.

In the boundary mode, the SC falls out of synchronism. According to (11), at $\delta=\pi / 4$, the moments are:

$$
\left|-M_{\text {s.bor }}\right|=M_{\text {r.max }}
$$

and for $\delta>\pi / 4$, the synchronizing torque is negative. Even in the absence of negative excitation, the angle $\delta>\pi / 4$ increases as the reactive torque decreases. For $\delta=\pi / 2$, i.e., when the rotor is positioned along the transverse axis, the stator resistance is equal to $\mathrm{X}_{\mathrm{q}}$, and the power consumption reaches the highest value (10) in the absence of excitation $(1 \mathrm{EX}=0)$.

$$
\begin{array}{r}
M_{s}=\frac{\mathrm{E}_{\mathrm{q}} \mathrm{U}_{\mathrm{In}}}{\mathrm{x}_{\mathrm{d}}} \cdot \sin \delta \\
M_{r}=\frac{\mathrm{U}_{\mathrm{m}}^{2}}{2} \cdot \frac{\mathrm{x}_{\mathrm{d}}-\mathrm{x}_{\mathrm{q}}}{\mathrm{x}_{\mathrm{d}} \mathrm{x}_{\mathrm{q}}} \cdot \sin 2 \delta
\end{array}
$$




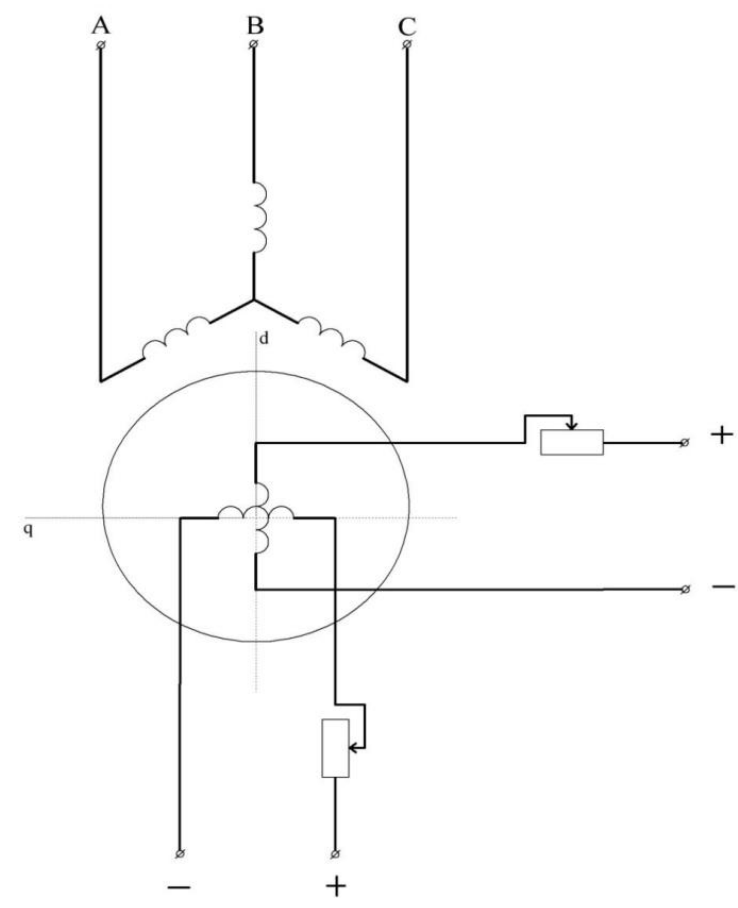

Fig-2. Schematic diagram of the longitudinal and transverse excitement of the synchronous compensator.

Such a regime is possible only under conditions of artificial stability of the SC [9].

Artificial stability of the SC operation when the rotor is located along the transverse axis is provided by the fast-acting alternating automatic control of the SC reversible excitation by deviations of the angle $\pm \Delta \delta$ from the boundary value $\delta_{\text {bor }}=\pi / 2$. The resulting positive or negative synchronizing torques decelerate or accelerate the rotor, which, while vibrating, is held in a dynamically balanced position along the transverse axis. The excitation winding of the SC, in this case, plays the role of only holding the rotor in the specified position. The same role of holding the rotor in position along the longitudinal axis, i.e., at angle $\delta=0$, and negative excitation can be performed by the second holding excitation winding located along the transverse axis of the rotor. Such SC with two excitation windings - the main longitudinal and the holding transverse - can be loaded with any limited, only thermal resistance of the stator windings, the consumed reactive power at the angle of the rotor position $\delta \approx 0$. [8]

\section{Conclusions}

1. Synchronous compensators with biaxial excitation, have high technical and economic indicators, provide the required voltage level at given points of the high-voltage and ultra-high-voltage networks (nodes of their connection) reduce the loss of electrical energy in power lines, solve the problem of increasing conductivity and stability.

2. In synchronous compensators with biaxial excitation, it is possible to smoothly and automatically adjust reactive power \pm Qsk in a wide range to increase and decrease the voltage relative to conventional synchronous compensators. 


\section{References}

1. Akhmatov M.G. Synchronous machines. Special course: Textbook. manual for technical colleges - M .: Higher school,- p 135. (1984)

2. Pirmatov N.B., Akhmatov M.G. Abnormal operating modes of synchronous machines with biaxial excitation. Tashkent: Publishing house of Tashkent State Technical University,.- p 158. (2003)

3. Osin L.G., Shakaryan Yu.G. Electric cars. Synchronous machines. Moscow. Higher school, - p 303. (1990).

4. Alekseev O. P. "Automation of electric power systems", M., "Energoizdat", (1981).

5. Berkovich M.A. "Automation of power systems", M .: "Energoatom-Izdat", Moscow, (1991).

6. Soloviev I.N. "Automatic regulators of synchronous generators", M., "Energoatomizdat", (1981).

7. N. Pirmatov, Sh. Toshev. Overvoltage in the free phase of the stator winding in case ofasymmetric short circuit implicit pole synchronous generator biaxial excitation. E3S Web of Conferences 139, 010 (2019).

8. Olimjon Toirov, Allabergan Bekishev, Sardor Urakov and Utkir Mirkhonov E3S Web of Conferences 216, 01116 (2020), https://doi.org/10.1051/e3sconf/202021601116

9. M.M. Fayziev, N.A. Kurbanov, A.B. Imomnazarov, B.S. Bobonazarov, A.E. Bekishev, Modeling non salient pole synchronous generator in Matlab. - Moscow. Bulletin of Science and Education No. 3 (27) Tom1, pp. 10-14. http://scientificjournal.ru (2017).

10. Fayziyev M.M., Qurbanov N.A., Imomnazarov A.B., Bekishev A.E. Simulation run asynchronous motor in Matlab. Moscow. Bulletin of Science and Education No. 5 (29) Tom1, pp. 42-47. http://scientificjournal.ru (2017).

11. R Karimov, A Rasulov, K Shamsiyev, A Bekishev, N Kurbanova, N. Musashayxova. IOP Conf. Series: Materials Science and Engineering 883 (2020) 012142. IOP Publishing doi: 10.1088 / 1757-899X / 883/1/012142.

12. Hadha Afrisal, Budi Setiyono, Muhammad Fahmi Yusuf, Rose Mutiara Suin, Olimjon Toirov 2020 7th International Conference on Information Technology, Computer, and Electrical Engineering (ICITACEE), pp. 41-46 (2020), https://doi.org/10.1109/ICITACEE50144.2020.9239228

13. Olimjon Toirov,Kamoliddin Alimkhodjaev, Nurali Pirmatov and Aziza Kholbutaeva

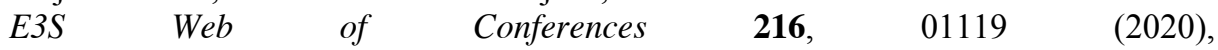
https://doi.org/10.1051/e3sconf/202021601119

14. Kamoliddin Alimkhodjaev, Olimjon Toirov, Mirzohid Taniev, Sharofiddin Alimkhodjaev Addressing Issues and Possibility of Introducing Renewable Energy Sources in the Conditions of Uzbekistan. JCR. 7(15), 1721-1728 (2020), doi:10.31838/jer.07.15.231

15. Dmitriy Bystrov, Toirov Olimjon, Mustafakulova Gulzoda, Yakubova Dilfuza NISS2020: Proceedings of the 3rd International Conference on Networking,

Information Systems \& Security, 54, P.1-3 (2020), https://doi.org/10.1145/3386723.3387873

16. Dmitriy Bystrov, Toirov Olimjon, Giyasov Sanjar, Taniev Mirzokhid, Urokov Sardor NISS2020: Proceedings of the 3rd International Conference on Networking, Information Systems \& Security, 49, P. 1-4 (2020), https://doi.org/10.1145/3386723.3387868

17. Kopylov, I.P. Mathematical modeling of electrical machines: ucheb. for universities / I.P. Kopylov. - M., - p 327. (2001). 
18. V.A. Denisov, M.N. Tretyakova. Theory and transition processes of electromagnetic devices and electromechanical transformers of energy. Electronic uchebnoe posobie. FGBOU VPO “Tolyatt State University” - p 108 (2014).

19. German-Galkin, S.G. Matlab \& Simulink. Design of mexatron systems on PK / S.G. German-Galkin. - SPb. : KORONA-Vek, - p 368. (2008).

20. O.Z. Toirov, A.E. Bekishev, M.X. Taniev/ Study of oscillatory stability of synchronous generators in Matlab environment / Informatika va energetika problemslari, №5.str 70-77, (2019) 